\title{
Menarche and Menopause among the Yanadi Tribal Women
}

\author{
Chandrika $\mathrm{T}^{1} \&$ Adilakshmi $\mathrm{T}^{2}$ \\ ${ }^{1}$ Research Scholar, Department of Anthropology, Sri Venkateswara University, Tirupati 517502, Andhra \\ Pradesh, India \\ ${ }^{2}$ Research Scholar, Centre for Extension Studies and Women Studies, Sri Venkateswara University, Tirupati \\ 517502, Andhra Pradesh, India
}

\begin{abstract}
Menarche and menopause are two important events in women's life, and they are accompanied by many morphological and physiological changes in the body. The onset of menarche in girls signifies the attainment of sexual maturity. The period of menopause is also important, as it is marked by the arrest of ovulation and menstruation flow and indicates cessation of reproductive function. In the present study an attempt has been made to study the age at menarche and menopause among the Yanadi women of Nellore district, Andhra Pradesh. The mean menarcheal and menopausal age of Yanadi women was found to be $13.46 \pm$ 1.094 years and $44.68 \pm 2.765$ years respectively.
\end{abstract}

Keywords: Menarche, Menopause, Yanadi, Variation

\section{Introduction}

Menarche and menopause are two important events in women's reproductive as well as social and cultural life. These events are accompanied by many morphological and physiological changes in the body. Menarche is the onset of menstruation or the first menstrual bleeding among the girls. Its commencement indicates the attainment of sexual ripeness and fecundity. It is highly correlated with other pubertal characteristics (breast development, pubic hair development, body growth, menarche, auxiliary hair growth, sweat glands) and is, therefore preferred as a benchmark for sexual maturation. It usually begins at puberty and continues until menopause. The Menarche and menopause are two important biological and physiological events, which occur in the life cycle of every normal female. They are accompanied by many morphological, physiological changes in the body. The term menarche introduced into medical literature by Kisch. ${ }^{(1)}$

Menopause is a gradual process in the life of a woman when her monthly periods get abnormally delayed, become irregular and completely stop happening at some point of time. It is a normal part of aging and marks the end of a woman's reproductive years as it is noticeable by the termination of ovulation and menstrual periods. The age at menopause also vary widely between and within populations and are influenced by multitude of genetic, socio-cultural and environmental factors. Menopause is diagnosed when a woman has gone without a period for 12 consecutive months. Menopause typically occurs in a woman's late 40 s to early 50s. Some individuals experience premature menopause. Women who are reaching a stage of menopause or reached menopause experience some changes like hot flashes (a sudden feeling of warmth that spreads over the upper body), vaginal dryness; discomfort during sex, urinary urgency, difficulty sleeping, emotional changes (irritability, mood swings, mild depression)etc.

The differences in the ages at menarche and menopause and various related issues have provoked interest among the scientists to carry out studies in different populations exploring trends, and various determinants.

The goal of the present study is to determine the onset of menarcheal age and menopause among the endogamous population of Yanadi tribal woman in Nellore District of Andhra Pradesh.

\section{The Yanadi}

The Yanadi is one of the major tribe predominantly distributed in Nellore District of Andhra Pradesh. There are about 351,676 Yanadi living in eight districts of Andhra Pradesh (Census 2001), of which more than fifty percent live in Nellore District. The very name Yanadi is said to have been derived from 'anadi' or "people without a beginning". The ancestors of the Yanadi are believed to be 'hunter-gatherer-fisher' people. Presently the Yanadi pursue a multitude of occupations of which agricultural labour is widely practiced. The Yanadi are a tribe inhabiting the plain areas. In particular they inhabit in separate habitations, locally known as colony or gumpu (group) in the rural areas of the district. While a few settlements are independent and isolated others are located in clearly demarcated sites away from the agricultural caste villages. They speak a dialect of their own among themselves, which is very close to Telugu language. 
One conspicuous feature of the Yanadi family is its wide network of kin. Visiting the kin quite frequently is figuratively an obsession with the Yanadi. Socio-economically the Yanadi are much less differentiated among themselves mainly due to their ethnic identity which they preserve through speaking their dialect, observation of some cultural practices like serial monogamy, bilateral kinship extensions, rangam (divination conducted for invoking the ancestors and several gods and deities for intervention in all kinds of life risks), vesham (hilarious guises and obscene dances during all life cycle events, small or big/ sad or happy occasions) etc. They do work and interact with the caste villagers particularly in economic affairs. But they maintain their cultural identity. They do not show much interest in education, secular employments and political spheres etc.

Yanadi tribal women enjoy considerable gender equality though the tribe is patrilineally organized and inheritance of property is passed in male line. Usually girl child is loved as much as the boy and discrimination between male and female children is not noticed. The girls carry an implicit value as potential spouses proliferating the progeny and kinship ties. Girls are given all assistance not only by parents but by various kin members.

\section{Material And Methods}

In the present study, data from 400 women belonging to the Yanadi tribal women were collected for menarcheal and menopausal ages from 16 villages in Nellore district, Andhra Pradesh. These women are more or less socio-economically homogeneous. Women were asked to reveal their age at menarche and age at menopause. While all the 400 women attained menarche, 83 women reported attainment of menopause. Necessary data were obtained from the subjects by retrospective method depending on recall.

\section{Menarche}

\section{Results And Discussion}

In the present study, the analysis of the data reveals that the maximum number of Yanadi women attained menarche at the age of $13(36.8 \%)$ and 14 years $(27.3 \%)$. The range of variation is 11 to 18 years, and the mean onset of menarche is reported to occur at $13.46 \pm 1.094$ years. The comparative figures of mean menarcheal age of women of different tribes are as follows: 12.08 years in Gonds of Madhya Pradesh (Sharma, $1995)^{(2)} ; 15.00$ years among the Abujhmaria of Madhya Pradesh (Pandey et al., 1999) ${ }^{(3)} ; 13.93$ years among the Iruliga of Karnataka (Dakshayani 2007) ${ }^{(4)} ; 13.93$ years among the Tangkhul Naga $\left(\right.$ Chakravarti,1986) ${ }^{(5)} ; 14.13$ years among the Zemi Naga (Bhowmik et al.,1971) ${ }^{(6)} ; 15.00$ years among the Angami Naga $\left(\right.$ Suri, 1985) ${ }^{(7)}$ and 15.15 years among the Kabui Naga $\left(\right.$ Chakravarti, 1986) ${ }^{(5)}$.

Table 1: Age at menarche among the Yanadi women

\begin{tabular}{|c|c|c|c|}
\hline Age group & Number & Percent & Mean \pm S.D \\
\hline 11 & 5 & 1.3 & \\
12 & 70 & 17.5 & \\
13 & 147 & 36.8 & \\
14 & 109 & 27.3 & $13.46 \pm 1.094$ \\
15 & 58 & 14.5 & \\
16 & 8 & 2 & \\
17 & 2 & 0.8 & \\
18 & 1 & 0.3 & \\
\hline Total & $\mathbf{4 0 0}$ & $\mathbf{1 0 0}$ & \\
\hline
\end{tabular}

\section{Menopause}

In the present study, the age of menopause among the Yanadi women ranges from 38 to 51 years. Most of the Yanadi women reach menopause at the age of 44 years (20.00\%). The mean age at menopause is $44.68 \pm$ 2.765 years. The mean menopausal age of the present Yanadi sample is compared with other tribal population. The mean age at menopausal varies from in the other tribal population it varies from 43 years among Kamars (Biswas et al., 2001) ${ }^{(8)}$ to 51.33 years among Ao Nagas of Nagaland (Purnungala et al., 2002) ${ }^{(9)}$. The mean age at menopause is 46.63 years among Iruliga tribe (Dakshayani et al., 2007) ${ }^{(4)}$ to the mean age at menopause is 44.6 years years among Saharia tribe (Biswas et al., 2004) ${ }^{(10)}$. The differences in age at menopause in different population may be influenced by genetical and environmental factors. Malnutrition low socio-economic factors, rural residence, family size etc. may be attributed to the possible reasons for determining the menopausal age of women (Frisch, 1974 $4^{(11)}$; Bongaarts, 1980 ${ }^{(12)}$; Beall, 1983 ${ }^{(13)}$; Sengupta and Rajkhowa, 1996 ${ }^{(14)}$; Kalita and Sengupta, $1997^{(15)}$; Biswas and Kapoor, 2003) $)^{(16)}$. 
Table 2: Age at menopause among the Yanadi women

\begin{tabular}{|c|c|c|c|}
\hline Age group & Number & Percent & Mean \pm S.D \\
\hline 38 & 1 & 1.17 & \\
39 & 2 & 2.35 & \\
40 & 5 & 5.88 & \\
41 & 2 & 2.35 \\
42 & 7 & 8.23 & \\
43 & 7 & 8.23 & $44.68 \pm 2.765$ \\
44 & 17 & 20 & \\
45 & 15 & 17.64 & \\
46 & 8 & 9.41 & \\
47 & 7 & 8.23 & \\
48 & 6 & 4.05 & \\
59 & 4 & 3.52 & \\
51 & 3 & 1.17 & $\mathbf{1 0 0}$ \\
\hline Total & 1 & & \\
\hline
\end{tabular}

The informants have cited some problems after reaching menopause: moodiness, absentmindedness, lack of attentiveness, sleeplessness, headache, and depression. The women confessed that they fail to understand what is happening to her.

In the present study mean ages at menarche and menopause of women are varied in view of different background factors like nutritional status, size of the family, medical facilities, educational levels, living standards, socio-economic condition, etc.

\section{Conclusion}

In the present study, most of the Yanadi woman attained menarche between 13 and 14 years. The mean menarcheal age of the Yanadi women in the study was 13.68 years and mean menopausal was 44.68 years. A lack of nutritional status during childhood period cause late menarche. So lower the socio-economic status, the higher the age at menarche. This might be the influence of nutritional diet intake along with other environmental factors among Yanadi women. Malnutrition, lack of medical facilities, environmental changes, low socioeconomic status, etc. may be assessed as the attributed reasons of the low mean age at menopause of Yanadi women.

\section{References}

[1] Kish EH 1910. The Sexual Life of Women in the Physiological, Pathological and Hygiene Aspects. London: Rehman Ltd.

[2] Sharma, M.B. and Choudhary, Dipesh.: Menarche and fertility. A correlation study among the Gond tribe of Maharashtra, J. Hum. Ecol., 6(3): 209-212 (1995).

[3] Pandey, G.D. and Goel, A.K.: Some demographic charactericts of Abujhmaria of Madhya Pradesh. J. Hum. Ecol., 10(2): 85-88 (1999).

[4] B. Dakshayani*, M. Satish Chandran and M. R. Gangadhar: Menarche and Menopause among the Iruliga Tribal Women, Anthropologist, 9(3): 255-256 (2007).

[5] Chakravarty, R.: The People of Manipur. B.R. Publishing Company, Delhi (1986).

[6] Bhowmik,K.L., Choudhury, M. K., Das, P. and Choudhury, K.K.: Fertility of Zemi Women of Nagaland. Institute of Social Studies, Calcutta (1971).

[7] Suri, R.: Physical Anthropology of the Angami Naga: A Tribe of North East India. Unpublished Ph.D. Thesis, Gauhati University, Guwahati (1985).

[8] Biswas, Ranjan Kumar, Patra, Prasanna Kumar and Kapoor, A.K.: Demographic profile of Kamar- A primitive tribe of Madhya Pradesh. Bulletin of the Tribal Research Institute Bhopal, XXVIII (1 and 2): 67-77 (2001).

[9] Purnungla and Sarthak Sengupta: Menarche and Menopause Among The Ao Naga Women of Nagaland, India. J. Hum. Ecol., 13(4): 323-324 (2002).

[10] Biswas RK; Kapoor AK: Age at menarche and menopause among Saharia women -a primitive tribe of Madhya Pradesh. Anthropologist. 2004; 6(4):247-252.

[11] Frisch, R.E.: A method of prediction of age of menarche from height-weight at ages 9 through 13 years. J. Pediatr., 53: 384 (1974).

[12] Bongaarts, J.E.: Does malnutrition affect fecundity: A summary of evidence. J. Science, 208: 564-569 (1980).

[13] Beall, C.M.: Ages at menopause and menarche in a high altitude Himalayan population. Ann. Hum. Biol.,10: 365 (1983).

[14] Sengupta, S and M. Rajkhowa: Menarche and menopause among the Ahom women of Dibrugarh, Assam. Journal of Human Ecology, 7: 211-213 (1996).

[15] Kalita, Mondira and Sengupta, Sarthak: Age at Menarche and menopause among the Sonowal Women of Dibrugarh, Assam. J. Hum. Ecol., 8(6): 485-486 (1997).

[16] Biswas, Ranjan Kumar and Kapoor, A.K.: fertility profile of a primitive tribe, Madhya Pradesh. Anthropologist, 5(3): 161-167 (2003). 